\title{
Relationship between attention-deficit hyperactivity disorder symptoms and problem gambling: A mediation analysis of influential factors among 7,403 individuals from the UK
}

\author{
LOUIS JACOB ${ }^{1 *}$, JOSEP MARIA HARO ${ }^{2,3}$ and AI KOYANAGI ${ }^{2,3}$ \\ ${ }^{1}$ Faculty of Medicine, University of Paris 5, Paris, France \\ ${ }^{2}$ Research and Development Unit, Parc Sanitari Sant Joan de Déu, Fundació Sant Joan de Déu, Universitat de Barcelona, Barcelona, Spain \\ ${ }^{3}$ Instituto de Salud Carlos III, Centro de Investigación Biomédica en Red de Salud Mental, CIBERSAM, Madrid, Spain
}

(Received: April 7, 2018; revised manuscript received: May 30, 2018; second revised manuscript received: June 16, 2018; accepted: June 19, 2018)

\begin{abstract}
Background and aims: Our goal was to examine the association between attention-deficit hyperactivity disorder (ADHD) symptoms and gambling problems, and to identify potential mediating factors of this association. Methods: This study used cross-sectional, community-based data from 7,403 people aged $\geq 16$ years who participated in the Adult Psychiatric Morbidity Survey 2007. ADHD symptoms were assessed using the Adult ADHD Self-Report Scale (ASRS) Screener. Problem gambling was assessed using a questionnaire based on the 10 DSM-IV diagnostic criteria for pathological gambling. Respondents were classified as having no problem, at-risk, or problem gambling. Logistic regression and mediation analyses were conducted to analyze the association between ADHD symptoms (i.e., ASRS score $\geq 14$ ) and problem gambling and the role of several variables in this association. Results: The prevalence of at-risk ( $5.3 \%$ vs. $2.4 \%)$ and problem gambling $(2.4 \%$ vs. $0.6 \%)$ was higher in individuals with ADHD symptoms than in those without ADHD symptoms. ADHD symptoms were significantly associated with both at-risk $(\mathrm{OR}=2.15$; $95 \% \mathrm{CI}=1.22-3.79)$ and problem gambling $(\mathrm{OR}=3.57 ; 95 \% \mathrm{CI}=1.53-8.31)$ when adjusted for age, sex, and ethnicity. Common mental disorders (CMDs; i.e., depression and anxiety disorders) (mediated percentage $=22.4 \%$ ), borderline personality disorder (BPD) traits $(22.1 \%)$, stressful life events $(13.2 \%)$, stress at work or home (12.6\%), alcohol dependence (11.8\%), and impulsivity (11.2\%) were significant mediators in the ADHD-gambling association. Discussion and conclusions: Overall, ADHD symptoms were positively associated with problem gambling. CMDs, BPD traits, and stressful life events were important mediators in this relationship.
\end{abstract}

Keywords: attention-deficit hyperactivity disorder symptoms, problem gambling, risk factor, mediation analysis, United Kingdom

\section{INTRODUCTION}

Attention-deficit hyperactivity disorder (ADHD) is a neurodevelopmental disorder defined by inattention and hyperactivity-impulsivity (American Psychiatric Association, 2013; Stickley, Koyanagi, Takahashi, \& Kamio, 2016). Although ADHD was historically thought to be specific to childhood and adolescence (Zulauf, Sprich, Safren, \& Wilens, 2014), recent studies have shown that ADHD persists in adulthood in $40 \%-70 \%$ of cases (Biederman, Petty, Evans, Small, \& Faraone, 2010; Ebejer et al., 2012). The persistence of ADHD in adulthood has been found to lead to the disruption of both the professional and personal life of patients (Harpin, 2005).

A longstanding literature has highlighted the link between ADHD and a variety of addictive behavior, but there is currently a notable growing interest in its association with gambling addiction (Abouzari, Oberg, Gruber, \& Tata, 2015; Aymamí et al., 2015; Brandt \& Fischer, 2017; Breyer et al., 2009; Chamberlain, Derbyshire, Leppink, \& Grant, 2015; Dai, Harrow, Song, Rucklidge, \& Grace, 2016; Faregh \& Derevensky, 2011; Fatseas et al., 2016; Ferguson \& Ceranoglu, 2014; Grall-Bronnec et al., 2011; Ostojic, Charach, Henderson, McAuley, \& Crosbie, 2014; Retz, Ringling, Retz-Junginger, Vogelgesang, \& Rösler, 2016; Rodriguez-Jimenez et al., 2006; Romo et al., 2015, 2016; Theule, Hurl, Cheung, Ward, \& Henrikson, 2016; Waluk, Youssef, \& Dowling, 2016). Although the underlying mechanism linking ADHD and gambling addiction is largely unknown, several hypotheses involving demoralization/ failure (Anselme \& Robinson, 2013; Baines, Jones, \& Christiansen, 2016), psychiatric conditions (Clarke, 2006; Sobanski, 2006), impulsivity (Fatseas et al., 2016), or

* Corresponding author: Dr. Louis Jacob; Faculty of Medicine, University of Paris 5, 15 rue de l'École de Médecine, Paris 75006, France; Phone: +33 6278837 06; E-mail: louis.jacob.contacts@ gmail.com

This is an open-access article distributed under the terms of the Creative Commons Attribution-NonCommercial 4.0 International License, which permits unrestricted use, distribution, and reproduction in any medium for non-commercial purposes, provided the original author and source are credited, a link to the CC License is provided, and changes - if any - are indicated. 
dysfunctions in the dopaminergic system (Blum et al., 2008; Ludolph et al., 2008) have been suggested. Previous studies, which found positive associations between ADHD and gambling, have advanced the field, but there are still notable gaps in the literature. First, most studies were of small sample size (Aymamí et al., 2015; Brandt \& Fischer, 2017; Breyer et al., 2009; Chamberlain et al., 2015; Dai et al., 2016; Ferguson \& Ceranoglu, 2014; Grall-Bronnec et al., 2011; Ostojic et al., 2014; Retz et al., 2016; Rodriguez-Jimenez et al., 2006; Waluk et al., 2016), used clinical samples (Aymamí et al., 2015; Brandt \& Fischer, 2017; Chamberlain et al., 2015; Dai et al., 2016; Ferguson \& Ceranoglu, 2014; Grall-Bronnec et al., 2011; Ostojic et al., 2014; Retz et al., 2016; Rodriguez-Jimenez et al., 2006; Waluk et al., 2016), or focused only on young adults (Breyer et al., 2009; Chamberlain et al., 2015; Faregh \& Derevensky, 2011; Ferguson \& Ceranoglu, 2014; Ostojic et al., 2014; Romo et al., 2015), while to the best of our knowledge, there are no studies using nationally representative data sets. This severely limits generalizability of their findings. Furthermore, there is very limited information on the factors that mediate the ADHD-gambling association. For example, impulsivity is one of the core features of ADHD (Miller, Derefinko, Lynam, Milich, \& Fillmore, 2010) and it is also highly implicated in the pathogenesis of gambling addiction (Hodgins \& Holub, 2015), but, to date, no study has quantified the extent to which this factor explains the link between ADHD and gambling. This is an important omission because there are effective treatments for impulsivity in ADHD and these treatments might help prevent the development of gambling addiction (Arns, de Ridder, Strehl, Breteler, \& Coenen, 2009). Furthermore, the degree of contribution of factors, such as sociodemographics (e.g., marital status or employment), unhealthy behaviors (e.g., smoking status, alcohol dependence, or drug use), intelligence, comorbid mental diseases (e.g., depression or anxiety), borderline personality disorder (BPD) traits, stressful life events, and stress at work or home in this association, is also insufficiently understood, despite their previously reported strong association with both ADHD and gambling. ADHD is known to cause disruptions in the personal and professional life of people with this condition (Harpin, 2005), and these disruptions might result in higher odds of gambling addiction (Botterill, Gill, McLaren, \& Gomez, 2016; Feigelman, Kleinman, Lesieur, Millman, \& Lesser, 1995). Furthermore, individuals with ADHD are more likely to engage in unhealthy behaviors (McClernon \& Kollins, 2008; Wilens, 2004), and these behaviors might play an important role in the predisposition to future gambling addiction (del Pino-Gutiérrez et al., 2017; Petry \& Oncken, 2002; Wareham \& Potenza, 2010). Regarding intelligence, children with ADHD have been reported to have lower intelligence quotient (IQ) than control subjects (Biederman, Fried, Petty, Mahoney, \& Faraone, 2012), and in turn, people with lower IQ are at a higher risk of problem gambling (Rai et al., 2014). In addition, there has been some literature showing that ADHD is strongly associated with mental disorders and BPD (Becker, Langberg, Evans, Girio-Herrera, \& Vaughn, 2015; Davidsson et al., 2017; Matthies \& Philipsen, 2014), while some authors have suggested that these disorders might be key players in the subsequent onset of gambling addiction (Clarke, 2006; Oliva et al., 2017). Finally, stressful life events and stress are frequently found in people with ADHD (Vrijsen et al., 2017), and they are often considered as strong motivations for gambling (Biback \& Zack, 2015).

Therefore, our goal was to examine the association between ADHD symptoms and gambling problems, and to identify potential mediating factors (sociodemographic, behavioral, and psychological) of this association using nationally representative community-based data from the Adult Psychiatric Morbidity Survey (APMS) 2007. Given the high prevalence of gambling disorder in the United Kingdom (UK; Gambling Commission, 2018), investigating risk factors such as ADHD in this setting is important for the development of prevention and management strategies for gambling problems.

\section{METHODS}

\section{Study participants}

This study used data from 7,403 people who participated in the APMS 2007. Full details of the survey have been published elsewhere (Jenkins et al., 2009; McManus, Meltzer, Brugha, Bebbington, \& Jenkins, 2009). Briefly, this was a nationally representative survey of the English adult population (aged $\geq 16$ years) living in private households. The National Center for Social Research and Leicester University undertook the survey fieldwork from October 2006 to December 2007 using a multistage-stratified probability sampling design where the sampling frame consisted of the small user postcode address file, while the primary sampling units were postcode sectors. Participant information was obtained through face-to-face interviews where some of the questionnaire items were self-completed (with the use of a computer). Sampling weights were constructed to account for non-response and the probability of being selected, so that the sample was representative of the English adult household population. The survey response rate was $57 \%$.

\section{Measures}

ADHD symptoms. ADHD symptoms were assessed using the Adult ADHD Self-Report Scale (ASRS) Screener (Kessler et al., 2007). This is the 6-item version of a longer 18-item scale that assesses DSM-IV criterion ADHD symptoms in adults (Kessler et al., 2005). Specifically, six questions were asked about inattention (four items) and hyperactivity (two items) in the previous 6 months. A 5 -point response scale with answer options ranging from "never" - scored 0 to "very often" - scored 4 was used to grade responses. Scores from the individual items were added to give a total score that ranged from 0 to 24 . Using previous research as a guide to categorize scores (Kessler et al., 2005, 2007), in this study, we dichotomized scale scores with a score of 14 and above being used to signify the possible presence of ADHD. An earlier validation study among subscribers to a large health plan in the US showed a good specificity (0.94) and moderate sensitivity (0.65) for 
the ASRS Screener using the 0-24 scoring approach with a cut-off score of 14 (Kessler et al., 2007). Although our definition of ADHD was based on a screener, we refer to this condition as ADHD in the subsequent text for the sake of brevity.

Problem gambling. Problem gambling was assessed using a questionnaire based on the 10 DSM-IV diagnostic criteria for pathological gambling (Cowlishaw \& Kessler, 2016; Wardle, Griffiths, Orford, Moody, \& Volberg, 2012). There were two steps in the diagnosis of problem gambling. In the first step, participants were asked if they had spent money on gambling in the previous year. If participants answered "yes," they were administered the questionnaire, which consisted of 10 items. Respondents were classified as having no problem ( 0 criteria), at-risk ( 1 or 2 criteria), or problem gambling ( $\geq 3$ criteria). Despite the cut-off being arbitrary and approximate, this cut-off allows for an estimation of the severity of gambling and has been used in past APMS publications (Cowlishaw \& Kessler, 2016; Jacob, Haro, \& Koyanagi, 2018c; Rai et al., 2014).

Mediating variables. This study included several mediating variables [marital status (Botterill et al., 2016; Harpin, 2005), employment (Feigelman et al., 1995; Harpin, 2005), smoking status (McClernon \& Kollins, 2008; Petry \& Oncken, 2002), alcohol dependence (del Pino-Gutiérrez et al., 2017; Wilens, 2004), drug use (Wareham \& Potenza, 2010; Wilens, 2004), IQ (Biederman et al., 2012; Rai et al., 2014), common mental disorders (CMDs; depressive episode and/or anxiety disorders) (Becker et al., 2015; Clarke, 2006; Davidsson et al., 2017), BPD traits (Matthies \& Philipsen, 2014; Oliva et al., 2017), perceived stress and the number of stressful life events (Biback \& Zack, 2015; Vrijsen et al., 2017), and impulsivity (Hodgins \& Holub, 2015; Miller et al., 2010)], which may be associated with or be the consequence of ADHD, and also be the cause of gambling problems.

Sociodemographic variables. Two variables were included: marital status (married/cohabiting and single/widowed/ divorced/separated) and employment (yes/no).

Smoking status. Participants were asked about their smoking activity and were classified as never smokers (never) or past/current smokers (quit/current).

Alcohol dependence. Excessive alcohol consumption was screened using the Alcohol Use Disorders Identification Test (AUDIT; Saunders, Aasland, Babor, de la Fuente, \& Grant, 1993). Alcohol dependence was assessed using the Severity of Alcohol Dependence Questionnaire in participants with an AUDIT score of 10 or above (Stockwell, Sitharthan, McGrath, \& Lang, 1994). Scores of four or above indicated alcohol dependence in the past 6 months.

Drug use. Each individual was asked if he/she had used one of the following drugs in the past year: cannabis, amphetamines, cocaine, crack, ecstasy, heroin, acid or LSD, magic mushrooms, methadone or physeptone, tranquilizers, amyl nitrate, anabolic steroids, and glues. Those who used at least one of these drugs were considered to be drug users (Jacob, Haro, \& Koyanagi, 2018a).
Intelligence quotient (IQ). Verbal IQ was estimated using the National Adult Reading Test (NART). The NART, a brief measure administered only to native English speakers and widely used in the world, consists of a list of 50 words and is scored by counting the number of errors made while reading out the words (Ali et al., 2013; Rai et al., 2014). There were 531 participants who were not administered the test (e.g., English not being their first language, eyesight problems, dyslexia, or refusal). IQ ranged from 70 to 127 . Verbal IQ is referred to as IQ in this manuscript for the sake of brevity.

Common mental disorders (CMDs). CMDs were assessed using the Clinical Interview Schedule Revised, and referred to depressive episode and/or anxiety disorders (generalized anxiety disorder, panic disorder, phobia, and obsessive-compulsive disorder) in the prior week (Stickley \& Koyanagi, 2016).

$B P D$ traits. The presence of the nine diagnostic criteria for BPD was assessed by the Structured Clinical Interview for DSM-IV Axis II disorders (SCID-II; First, Gibbon, Spitzer, Williams, \& Benjamin, 1997). The scores from each of the criteria (yes $=1$ and no $=0$ ) were added to create a scale ranging from 0 to 9 (Cronbach's $\alpha=.74$ ). Following the lead of a previous publication using the same data set (Kelleher, Ramsay, \& DeVylder, 2017), the cut-off to represent high BPD traits was based on a figure that corresponds to a prevalence, which is approximately 10 times greater than that of BPD $(0.4 \%$ in this data set). Specifically, a score of $\geq 6$ was used as the cut-off. Owing to the fact that there were only 16 individuals with BPD in our data set, we were unable to conduct meaningful analyses with BPD. Thus, we rather focused on high BPD traits.

Stressful life events. Eighteen items were used to assess different stressful life events (e.g., serious illness, death of an immediate family member, or major financial crises) (Jacob, Haro, \& Koyanagi, 2018b). We first checked the bivariate association between individual stressful life events and ADHD and only included those who were significantly associated with ADHD in the summed scale. Specifically, three items were not significantly associated with ADHD: "death of an immediate family member," "death of a close family friend/other relative," and "being made redundant or sacked from your job." Therefore, the scale ranged from 0 to 15 .

Stress at work or home. Participants were asked if their tasks at home and at work were stressful. Answers ranged from 0 "not at all" to 3 "most of the time" (Wickham, Taylor, Shevlin, \& Bentall, 2014). Stress was then dichotomized into "not at all" versus "occasionally," "usually," and "most of the time."

Impulsivity. Impulsivity was assessed using the following question: "Have you often done things impulsively?" in relation to the "kind of person you generally are" (Carrà, Crocamo, \& Bebbington, 2017; Peters, Balbuena, Baetz, Marwaha, \& Bowen, 2015; Peters, Baetz, Marwaha, Balbuena, \& Bowen, 2016; Peters, Balbuena, 
Marwaha, Baetz, \& Bowen, 2015; Rai et al., 2014). This question was from the SCID-II.

Control variables. There were three control variables: sex (male and female), age (16-34, 35-59, and $\geq 60$ years), and ethnicity (British White or other).

\section{Statistical analyses}

Differences in the sample characteristics by ADHD status were tested using $\chi^{2}$ tests and Student's $t$-tests for categorical and continuous variables, respectively. We conducted multinomial logistic regression analysis to assess the association between ADHD (exposure variable) and problem gambling (outcome variable). Hierarchical analysis was performed to examine the effect of the inclusion of different variables in the model. Thus, six models were constructed: Model 1 - adjusted for sex, age, and ethnicity; Model 2 adjusted for variables in Model 1 and marital status and employment; Model 3 - adjusted for variables in Model 2 and smoking status, alcohol dependence, and drug use; Model 4 - adjusted for variables in Model 3 and IQ; Model 5 - adjusted for variables in Model 4 and the number of stressful life events; and Model 6 - adjusted for variables in Model 5 and CMDs, BPD traits, and stress at work or home. Given the overlap between BPD traits and impulsivity, we did not construct a model including both BPD traits and impulsivity to avoid multicollinearity.

Next, mediation analysis was conducted to assess the specific contribution of marital status, employment, smoking status, alcohol dependence, drug use, IQ, CMDs, BPD traits, number of stressful life events, stress at work or home, and impulsivity in the ADHD-gambling relationship. For this analysis, the gambling variable was dichotomized into "no problem" and "at-risk/problem" due to the small number of people with problem gambling. We used the khb (Karlson Holm Breen) command in Stata for this purpose (Breen, Karlson, \& Holm, 2013). This method can be applied in logistic regression models and decomposes the total effect (i.e., unadjusted for the mediator) of a variable into direct (i.e., the effect of ADHD on at risk/ problem gambling adjusted for the mediator) and indirect effects (i.e., the mediational effect). Using this method, the percentage of the main association explained by the mediator can also be calculated (mediated percentage). The mediators were individually included in the models. The mediation analysis was controlled for sex, age, and ethnicity.

All variables in the regression analyses were categorical variables with the exception of IQ and the number of stressful life events. The sample weighting and the complex study design were considered in all analyses. The level of statistical significance was set at $p<.05$. All analyses were performed using Stata version 13.1 (Stata Corp LP, College Station, TX, USA).

\section{Ethics}

Ethical permission for the study was obtained from the Royal Free Hospital and Medical School Research Ethics Committee. All participants provided informed consent before their inclusion. The data of this survey are available online (UK Data Archive and National Center for Social Research (Colchester, Essex, UK).

\section{RESULTS}

This study included 7,403 participants. The characteristics of the sample are displayed in Table 1 . Men constituted $48.6 \%$ of the sample, and $42.8 \%$ of the population were aged between 35 and 59 years. The prevalence of at-risk $(5.3 \%$ vs. $2.4 \%)$ and problem gambling $(2.4 \%$ vs. $0.6 \%)$ was higher in individuals with ADHD than in those without ADHD (Figure 1). The results of the multinomial logistic regression models are shown in Table 2. ADHD was significantly associated with both at-risk $(\mathrm{OR}=2.15$; $95 \% \mathrm{CI}=1.22-3.79$ ) and problem gambling in the model adjusted for age, sex, and ethnicity $(\mathrm{OR}=3.57$; 95\% $\mathrm{CI}=1.53-8.31$ ) (Model 1). These ORs were gradually attenuated with the inclusion of potential mediators and were no longer significant after adjustment for at least sociodemographics, unhealthy behavior, and IQ (Models 4-6). The results of the mediation analysis are displayed in Table 3. CMDs (mediated percentage $=22.4 \%$ ), BPD traits $(22.1 \%)$, stressful life events $(13.2 \%)$, stress at work or home $(12.6 \%)$, alcohol dependence $(11.8 \%)$, and impulsivity $(11.2 \%)$ were significant mediators in the association between ADHD symptoms and problem gambling.

\section{DISCUSSION}

\section{Main findings}

This nationally representative community-based study found that the prevalence of at-risk and problem gambling was higher in people with ADHD than in those without ADHD. It also showed that the strongest significant mediators in the ADHD-gambling association were CMDs, BPD traits, and stressful life events.

\section{Interpretation of the findings}

Despite previous literature pointing to the potentially important role of impulsivity in the relation between ADHD and problem gambling, in this study, CMDs and BPD traits explained a larger proportion of the association with each of these factors explaining about a quarter of the association. This may not be surprising given that $65 \%-89 \%$ of individuals with ADHD have been reported to suffer from at least one additional psychiatric condition, the most frequent ones being mood and anxiety disorders, substance-use disorders, and personality disorders (Sobanski, 2006). Moreover, people affected by childhood ADHD are at an increased risk of personality disorders, such as borderline, antisocial, avoidant, and narcissistic personality disorders (Miller et al., 2008). On the other hand, almost two third of people with problem gambling display a lifetime comorbid psychiatric disorder (i.e., mood disorders, adjustment disorder, or substance-use disorders) (Shek, Chan, \& Wong, 2012). Other authors have further estimated that approximately $32 \%$ of 
Table 1. Sample characteristics (overall and by ADHD status)

\begin{tabular}{|c|c|c|c|c|c|}
\hline \multirow[b]{2}{*}{ Characteristics } & \multirow[b]{2}{*}{ Category } & \multirow[b]{2}{*}{ Overall } & \multicolumn{2}{|c|}{ ADHD } & \multirow[b]{2}{*}{$p$ value $^{\mathrm{a}}$} \\
\hline & & & No & Yes & \\
\hline \multirow[t]{2}{*}{ Sex } & Male & 48.6 & 48.4 & 51.8 & .218 \\
\hline & Female & 51.4 & 51.6 & 48.2 & \\
\hline \multirow[t]{3}{*}{ Age (years) } & $16-34$ & 30.7 & 29.8 & 44.6 & $<.001$ \\
\hline & $35-59$ & 42.8 & 42.7 & 45.1 & \\
\hline & $\geq 60$ & 26.5 & 27.5 & 10.3 & \\
\hline \multirow[t]{2}{*}{ British White } & $\overline{\text { No }}$ & 14.9 & 14.8 & 16.0 & .564 \\
\hline & Yes & 85.1 & 85.2 & 84.0 & \\
\hline \multirow[t]{2}{*}{ Marital status } & Single/widowed/divorced/separated & 37.1 & 36.3 & 50.6 & $<.001$ \\
\hline & Married/cohabiting & 62.9 & 63.7 & 49.4 & \\
\hline \multirow[t]{2}{*}{ Employment } & No & 36.6 & 36.3 & 41.1 & .083 \\
\hline & Yes & 63.4 & 63.7 & 58.9 & \\
\hline \multirow[t]{2}{*}{ Smoking status } & Never & 34.8 & 34.9 & 32.5 & .392 \\
\hline & Quit/current & 65.2 & 65.1 & 67.5 & \\
\hline \multirow[t]{2}{*}{ Alcohol dependence } & No & 94.1 & 94.8 & 82.5 & $<.001$ \\
\hline & Yes & 5.9 & 5.2 & 17.5 & \\
\hline \multirow[t]{2}{*}{ Drug use } & No & 90.8 & 91.6 & 77.3 & $<.001$ \\
\hline & Yes & 9.2 & 8.4 & 22.7 & \\
\hline Intelligence quotient & Mean $(S D)$ & $102.4(15.2)$ & $102.7(15.2)$ & $98.7(15.6)$ & $<.001$ \\
\hline \multirow[t]{2}{*}{ Common mental disorders } & No & 92.1 & 93.9 & 63.2 & $<.001$ \\
\hline & Yes & 7.9 & 6.1 & 36.8 & \\
\hline \multirow[t]{2}{*}{ Borderline personality disorder traits } & No & 96.2 & 97.3 & 76.0 & $<.001$ \\
\hline & Yes & 3.8 & 2.7 & 24.0 & \\
\hline No. of stressful life events & Mean $(S D)$ & $1.9(2.0)$ & $1.8(1.9)$ & $3.3(2.5)$ & $<.001$ \\
\hline \multirow[t]{2}{*}{ Stress } & No & 39.4 & 40.9 & 14.1 & $<.001$ \\
\hline & Yes & 60.6 & 59.1 & 85.9 & \\
\hline \multirow[t]{2}{*}{ Impulsivity } & No & 68.2 & 69.4 & 47.2 & $<.001$ \\
\hline & Yes & 31.8 & 30.6 & 52.8 & \\
\hline
\end{tabular}

Note. ADHD symptoms were assessed using the six items from the Adult ADHD Self-Report Scale. Scores from the individual items were added to give a total score that ranged from 0 to 24. In this study, we dichotomized scale scores with a score of 14 and above being used to signify the possible presence of ADHD. Data are percentages for all variables except for intelligence quotient and the number of stressful life events (mean and $S D$ ). $S D$ : standard deviation; ADHD: attention-deficit hyperactivity disorder.

${ }^{a} p$ values were based on $\chi^{2}$ tests except for intelligence quotient and the number of stressful life events $(t$-tests).

pathological gamblers show at least one personality disorder (Fernández-Montalvo \& Echeburúa, 2004).

Furthermore, stressful life events, stress at work and home, alcohol dependence, and impulsivity explained $11 \%-13 \%$ of the relation between ADHD symptoms and problem gambling. Individuals with ADHD are more likely to be stressed, to experience stressful life events, and to display memory biases (Vrijsen et al., 2017). Regarding problem gambling, several sources of stress (i.e., family problems, relationship difficulties, or financial worries) have been found to favor the risk of developing this addiction and to even play a role in the decision-making process (Biback $\&$ Zack, 2015). In the case of alcohol dependence and other addictive substances, ADHD is a common risk factor, which involves more rapid transition to dependence and longer dependence (Wilens, 2004). Finally, the evolution and the severity of problem gambling can be worsened by the consumption of alcohol (del Pino-Gutiérrez et al., 2017).

Although impulsivity only explained $11 \%$ of the ADHD-gambling association in this study, research has suggested that impulsivity plays an important role in this association (Theule et al., 2016). Engaging in risk-taking and sensation-seeking activities in impulsive people such as those with ADHD is considered as a way of alleviating the symptoms related to the chronic arousal state that characterizes ADHD (Liu et al., 2013). In line with the hypothesis that impulsivity plays a key role in the ADHD-gambling association, impulsive behaviors at the age of 12 were reported to be predictors of problem gambling behaviors in late adolescence (Vitaro, Arseneault, \& Tremblay, 1999).

In terms of factors that may link ADHD and gambling, which were not assessed in this study, it has been found, for example, that people diagnosed with ADHD display major decision-making deficits that may partly explain their vulnerability to addiction and particularly to gambling (Mowinckel, Pedersen, Eilertsen, \& Biele, 2015). Furthermore, the impact of ADHD on the risk of developing problem gambling might also be explained by deficits in executive functioning, which have been described in pathological gamblers by several authors (Ledgerwood et al., 2012; Marazziti et al., 2008; Reid, McKittrick, Davtian, \& Fong, 2012). In addition, one has to bear in mind that people diagnosed with ADHD and those diagnosed with problem gambling tend to prefer immediate over delayed 


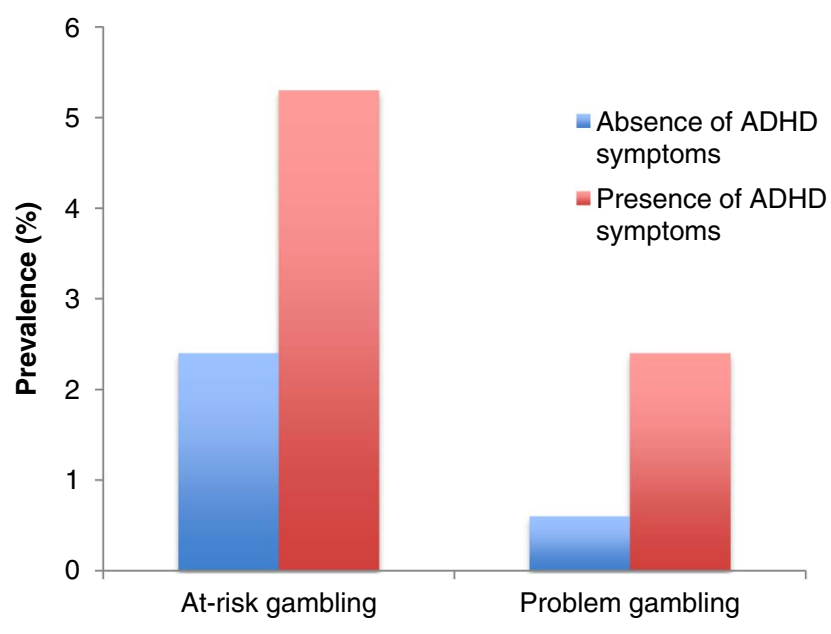

Figure 1. Prevalence of gambling problems by attention-deficit hyperactivity disorder (ADHD) status. ADHD symptoms were assessed using the 6 items from the Adult ADHD Self-Report Scale. Scores from the individual items were added to give a total score that ranged from 0 to 24 . In this study, a score of 14 and above was used to signify the possible presence of ADHD. Gambling status was assessed using 10 items from the DSM-IV criteria and the British Gambling Prevalence Survey studies.

Participants were classified as having "no problems" (0 criteria), "at-risk" (1-2 criteria), or "problem gambling" ( $\geq 3$ criteria)

gratification (Dixon, Jacobs, \& Sanders, 2006; Ernst et al., 2003). Next, ADHD is not only a risk factor for the development of problem gambling but also for the progression of the addiction itself (Theule et al., 2016). Finally, dysfunction in the dopaminergic system, which is observed in ADHD might lead to multiple drug-seeking behaviors and predispose patients to addiction, impulsivity, and compulsivity (Blum et al., 2008; Ludolph et al., 2008).

\section{Clinical implications}

The present findings indicate that screening for gambling problems among people with ADHD is important and that addressing CMDs, BPD traits, stressful life events, perceived stress, alcohol dependence, and impulsivity might lead to a reduction in the risk of at-risk/problem gambling in these individuals. People with ADHD should be screened for addictive behaviors such as gambling over the life course but particularly during adolescence, which is a critical period for the development of addictions. When an individual with ADHD is identified with problem gambling or high risk of it by his/her pediatrician or general practitioner, he/she should be referred to specialists such as addictologists and psychiatrists. Finally, a combination of psychotherapeutic and medical therapies, which is associated with an improvement in ADHD symptoms, might be of particular interest for the prevention of development of an addictive behavior in ADHD patients (Hesslinger et al., 2002; Philipsen et al., 2010).

\section{Strengths and limitations}

The large sample size and the use of nationally representative data are the main strengths of this work. Furthermore, it

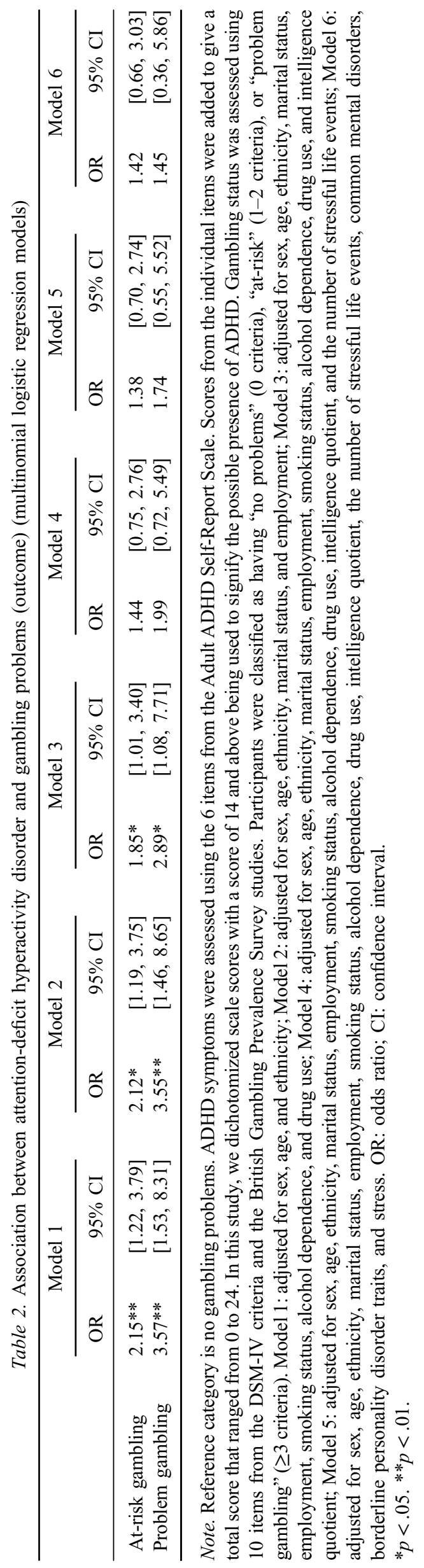


Table 3. Mediating factors in the association between attention-deficit hyperactivity disorder and gambling problems

\begin{tabular}{|c|c|c|c|c|c|c|c|}
\hline \multirow[b]{2}{*}{ Mediator } & \multicolumn{2}{|c|}{ Total effect } & \multicolumn{2}{|c|}{ Direct effect } & \multicolumn{2}{|c|}{ Indirect effect } & \multirow{2}{*}{$\begin{array}{c}\text { Mediated } \\
(\%)\end{array}$} \\
\hline & OR $[95 \% \mathrm{CI}]$ & $p$ value & OR $[95 \% \mathrm{CI}]$ & $p$ value & OR $[95 \% \mathrm{CI}]$ & $p$ value & \\
\hline Marital status & $2.48[1.51,4.09]$ & $<.001$ & $2.36[1.43,3.91]$ & .001 & $1.05[1.00,1.11]$ & .065 & NA* \\
\hline Employment & $2.46[1.49,4.04]$ & $<.001$ & $2.50[1.50,4.19]$ & $<.001$ & $0.98[0.92,1.05]$ & .586 & $\mathrm{NA}^{*}$ \\
\hline Smoking status & $2.45[1.48,4.05]$ & $<.001$ & $2.42[1.47,4.00]$ & .001 & $1.01[0.98,1.05]$ & .544 & NA* \\
\hline Alcohol dependence & $2.40[1.44,3.99]$ & .001 & $2.16[1.29,3.63]$ & .004 & $1.11[1.03,1.19]$ & .007 & 11.8 \\
\hline Drug use & $2.37[1.43,3.94]$ & .001 & $2.26[1.36,3.77]$ & .002 & $1.05[0.98,1.12]$ & .153 & $\mathrm{NA}^{*}$ \\
\hline Intelligence quotient & $2.04[1.17,3.54]$ & .011 & $1.86[1.07,3.24]$ & .028 & $1.10[1.00,1.20]$ & .061 & NA* \\
\hline Common mental disorders & $2.41[1.45,4.01]$ & .001 & $1.98[1.13,3.48]$ & .018 & $1.22[1.04,1.43]$ & .015 & 22.4 \\
\hline $\begin{array}{l}\text { Borderline personality } \\
\text { disorder traits }\end{array}$ & $2.26[1.27,4.04]$ & .006 & $1.89[1.01,3.54]$ & .048 & $1.20[1.04,1.38]$ & .013 & 22.1 \\
\hline $\begin{array}{l}\text { Number of stressful } \\
\text { life events }\end{array}$ & $2.46[1.49,4.05]$ & $<.001$ & $2.18[1.29,3.70]$ & .004 & $1.13[1.01,1.26]$ & .039 & 13.2 \\
\hline Stress & $2.50[1.52,4.11]$ & $<.001$ & $2.23[1.34,3.71]$ & .002 & $1.12[1.02,1.23]$ & .014 & 12.6 \\
\hline Impulsivity & $2.22[1.30,3.77]$ & .003 & $2.03[1.18,3.47]$ & .010 & $1.09[1.01,1.18]$ & .029 & 11.2 \\
\hline
\end{tabular}

Note. ADHD symptoms were assessed using the six items from the Adult ADHD Self-Report Scale. Scores from the individual items were added to give a total score that ranged from 0 to 24 . In this study, we dichotomized scale scores with a score of 14 and above being used to signify the possible presence of ADHD. Gambling status was assessed using 10 items from the DSM-IV criteria and the British Gambling Prevalence Survey studies. Participants were classified as having "no problems" (0 criteria), "at-risk" (1-2 criteria), or "problem gambling" ( $\geq 3$ criteria). For the purpose of the mediation analysis, the gambling variable was dichotomized (at-risk and problem gambling were merged into one category). Model is adjusted for sex, age, and ethnicity. OR: odds ratio; CI: confidence interval.

* Mediated percentage was only calculated when the indirect effect was significant $(p<.05)$.

is, to the best of our knowledge, the first nationally representative community-based study that has quantified the extent to which various behavioral and psychological factors may mediate the ADHD-gambling association. Nonetheless, our findings should be interpreted in the light of several limitations. First, since ADHD symptoms and problem gambling were based on self-reports, and because there is a major stigma associated with mental disorders (Sartorius, 2007), it is possible that the prevalence of these conditions was underestimated. Second, ADHD was identified with the ASRS Screener and was not based on a clinical diagnosis. Third, the DSM nomenclature does not mention at-risk and problem gambling. In addition, the selected cut-off for gambling, despite its previous use (Cowlishaw \& Kessler, 2016), is arbitrary. Moreover, as gambling items were specifically administered to people who had gambled in the past 12 months, we might have underestimated the prevalence of problem gambling. One should also bear in mind that the UK gambling laws have changed since the time of the survey (2007), and this has led to changes in the prevalence of gambling. Thus, our results might not necessarily reflect the current situation in the UK. In addition, since impulsivity was assessed by a single question, it might explain why it was only a weak mediator. Therefore, the mediating role of impulsivity in this study can only be seen as a preliminary finding, which needs to be corroborated in future studies using more complete assessments of impulsivity. Furthermore, perceived stress was assessed by a non-validated single question. Thus, results could have differed with the use of more complete measures, such as the Perceived Stress Scale. Finally, since this work was cross-sectional, we were not able to infer a causal direction between ADHD and problem gambling.

\section{CONCLUSIONS}

Overall, ADHD symptoms were positively associated with problem gambling. CMDs, BPD traits, stressful life events, perceived stress, alcohol dependence, and impulsivity were significant mediating factors. In light of these results, people with ADHD should be regularly screened for the development of problem gambling, and further research should focus on the potential mediators involved in this association.

Funding sources: AK's work was supported by the Miguel Servet contract financed by the CP13/00150 and PI15/ 00862 projects, integrated into the National $\mathrm{R}+\mathrm{D}+\mathrm{I}$ and funded by the ISCIII - General Branch Evaluation and Promotion of Health Research - and the European Regional Development Fund (ERDF-FEDER). These funders had no role in the study design, collection, analysis and interpretation of the data; writing of the report; and the decision to submit the article for publication.

Authors' contribution: LJ and AK designed the study, managed the literature searches and analyses, undertook the statistical analysis, and wrote the first draft of the manuscript. JMH contributed to the design of the study and the correction of the manuscript. All authors contributed to and have approved the final version of the manuscript.

Conflict of interest: LJ, JMH, and AK declared no conflict of interest.

Acknowledgements: The authors would like to thank the National Center for Social Research and the University of 
Leicester who were the principal investigators of this survey. They would also like to thank the UK Data Archive, the National Center for Social Research, and other relevant bodies for making these data publically available. They bear no responsibility for this analysis or interpretation of this publically available data set.

\section{REFERENCES}

Abouzari, M., Oberg, S., Gruber, A., \& Tata, M. (2015). Interactions among attention-deficit hyperactivity disorder (ADHD) and problem gambling in a probabilistic reward-learning task. Behavioural Brain Research, 291, 237-243. doi:10.1016/j. bbr.2015.05.041

Ali, A., Ambler, G., Strydom, A., Rai, D., Cooper, C., McManus, S., Weich, S., Meltzer, H., Dein, S., \& Hassiotis, A. (2013). The relationship between happiness and intelligent quotient: The contribution of socio-economic and clinical factors. Psychological Medicine, 43(6), 1303-1312. doi:10.1017/ S0033291712002139

American Psychiatric Association. (2013). Diagnostic and statistical manual of mental disorders (5th ed.). Washington, DC: American Psychiatric Association.

Anselme, P., \& Robinson, M. J. F. (2013). What motivates gambling behavior? Insight into dopamine's role. Frontiers in Behavioral Neuroscience, 7, 182. doi:10.3389/fnbeh.2013.00182

Arns, M., de Ridder, S., Strehl, U., Breteler, M., \& Coenen, A. (2009). Efficacy of neurofeedback treatment in ADHD: The effects on inattention, impulsivity and hyperactivity: A metaanalysis. Clinical EEG and Neuroscience, 40(3), 180-189. doi:10.1177/155005940904000311

Aymamí, N., Jiménez-Murcia, S., Granero, R., Ramos-Quiroga, J. A., Fernández-Aranda, F., Claes, L., Sauvaget, A., GrallBronnec, M., Gómez-Peña, M., Savvidou, L. G., Fagundo, A. B., del Pino-Gutierrez, A., Moragas, L., Casas, M., Penelo, E., \& Menchón, J. M. (2015). Clinical, psychopathological, and personality characteristics associated with ADHD among individuals seeking treatment for gambling disorder. BioMed Research International, 2015, 965303. doi:10.1155/ 2015/965303

Baines, L., Jones, A., \& Christiansen, P. (2016). Hopelessness and alcohol use: The mediating role of drinking motives and outcome expectancies. Addictive Behaviors Reports, 4, 65-69. doi:10.1016/j.abrep.2016.11.001

Becker, S. P., Langberg, J. M., Evans, S. W., Girio-Herrera, E., \& Vaughn, A. J. (2015). Differentiating anxiety and depression in relation to the social functioning of young adolescents with ADHD. Journal of Clinical Child and Adolescent Psychology, 44(6), 1015-1029. doi:10.1080/15374416.2014.930689

Biback, C., \& Zack, M. (2015). The relationship between stress and motivation in pathological gambling: A focused review and analysis. Current Addiction Reports, 2(3), 230-239. doi:10. 1007/s40429-015-0064-9

Biederman, J., Fried, R., Petty, C., Mahoney, L., \& Faraone, S. V. (2012). An examination of the impact of attention-deficit hyperactivity disorder on IQ: A large controlled family-based analysis. Canadian Journal of Psychiatry, 57(10), 608-616. doi:10.1177/070674371205701005
Biederman, J., Petty, C. R., Evans, M., Small, J., \& Faraone, S. V. (2010). How persistent is ADHD? A controlled 10-year followup study of boys with ADHD. Psychiatry Research, 177(3), 299-304. doi:10.1016/j.psychres.2009.12.010

Blum, K., Chen, A. L.-C., Braverman, E. R., Comings, D. E., Chen, T. J., Arcuri, V., Blum, S. H., Downs, B. W., Waite, R. L., Notaro, A., Lubar, J., Williams, L., Prihoda, T. J., Palomo, T., \& Oscar-Berman, M. (2008). Attentiondeficit-hyperactivity disorder and reward deficiency syndrome. Neuropsychiatric Disease and Treatment, 4(5), 893-918. doi:10.2147/NDT.S2627

Botterill, E., Gill, P. R., McLaren, S., \& Gomez, R. (2016). Marital status and problem gambling among Australian older adults: The mediating role of loneliness. Journal of Gambling Studies, 32(3), 1027-1038. doi:10.1007/s10899-015-9575-5

Brandt, L., \& Fischer, G. (2017). Adult ADHD is associated with gambling severity and psychiatric comorbidity among treatment-seeking problem gamblers. Journal of Attention Disorders. Advance online publication. doi:10.1177/10870 54717690232

Breen, R., Karlson, K. B., \& Holm, A. (2013). Total, direct, and indirect effects in logit and probit models. Sociological Methods \& Research, 42(2), 164-191. doi:10.1177/00491 24113494572

Breyer, J. L., Botzet, A. M., Winters, K. C., Stinchfield, R. D., August, G., \& Realmuto, G. (2009). Young adult gambling behaviors and their relationship with the persistence of ADHD. Journal of Gambling Studies, 25(2), 227-238. doi:10.1007/ s10899-009-9126-Z

Carrà, G., Crocamo, C., \& Bebbington, P. (2017). Gambling, geographical variations and deprivation: Findings from the adult psychiatric morbidity survey. International Gambling Studies, 17(3), 459-470. doi:10.1080/14459795.2017.1355405

Chamberlain, S. R., Derbyshire, K., Leppink, E., \& Grant, J. E. (2015). Impact of ADHD symptoms on clinical and cognitive aspects of problem gambling. Comprehensive Psychiatry, 57, 51-57. doi:10.1016/j.comppsych.2014.10.013

Clarke, D. (2006). Impulsivity as a mediator in the relationship between depression and problem gambling. Personality and Individual Differences, 40(1), 5-15. doi:10.1016/j.paid. 2005.05.008

Cowlishaw, S., \& Kessler, D. (2016). Problem gambling in the UK: Implications for health, psychosocial adjustment and health care utilization. European Addiction Research, 22(2), 90-98. doi:10.1159/000437260

Dai, Z., Harrow, S.-E., Song, X., Rucklidge, J. J., \& Grace, R. C. (2016). Gambling, delay, and probability discounting in adults with and without ADHD. Journal of Attention Disorders, 20(11), 968-978. doi:10.1177/1087054713496461

Davidsson, M., Hult, N., Gillberg, C., Särneö, C., Gillberg, C., \& Billstedt, E. (2017). Anxiety and depression in adolescents with ADHD and autism spectrum disorders; correlation between parent- and self-reports and with attention and adaptive functioning. Nordic Journal of Psychiatry, 71(8), 614-620. doi:10.1080/08039488.2017.1367840

del Pino-Gutiérrez, A., Fernández-Aranda, F., Granero, R., Tárrega, S., Valdepérez, A., Agüera, Z., Håkansson, A., Sauvaget, A., Aymamí, N., Gómez-Peña, M., Moragas, L., Baño, M., Honrubia, M., Menchón, J. M., \& JiménezMurcia, S. (2017). Impact of alcohol consumption on clinical 
aspects of gambling disorder. International Journal of Mental Health Nursing, 26(2), 121-128. doi:10.1111/inm.12221

Dixon, M. R., Jacobs, E. A., \& Sanders, S. (2006). Contextual control of delay discounting by pathological gamblers. Journal of Applied Behavior Analysis, 39(4), 413-422. doi:10.1901/ jaba.2006.173-05

Ebejer, J. L., Medland, S. E., van der Werf, J., Gondro, C., Henders, A. K., Lynskey, M., Martin, N. G., \& Duffy, D. L. (2012). Attention deficit hyperactivity disorder in Australian adults: Prevalence, persistence, conduct problems and disadvantage. PLoS One, 7(10), e47404. doi:10.1371/journal. pone. 0047404

Ernst, M., Kimes, A. S., London, E. D., Matochik, J. A., Eldreth, D., Tata, S., Contoreggi, C., Leff, M., \& Bolla, K. (2003). Neural substrates of decision making in adults with attention deficit hyperactivity disorder. The American Journal of Psychiatry, 160(6), 1061-1070. doi:10.1176/appi.ajp.160.6.1061

Faregh, N., \& Derevensky, J. (2011). Gambling behavior among adolescents with attention deficit/hyperactivity disorder. Journal of Gambling Studies, 27(2), 243-256. doi:10.1007/ s10899-010-9211-3

Fatseas, M., Alexandre, J.-M., Vénisse, J.-L., Romo, L., Valleur, M., Magalon, D., Chéreau-Boudet, I., Luquiens, A., Guilleux, A., Groupe, J., Challet-Bouju, G., \& Grall-Bronnec, M. (2016). Gambling behaviors and psychopathology related to attentiondeficit/hyperactivity disorder (ADHD) in problem and nonproblem adult gamblers. Psychiatry Research, 239, 232-238. doi:10.1016/j.psychres.2016.03.028

Feigelman, W., Kleinman, P. H., Lesieur, H. R., Millman, R. B., \& Lesser, M. L. (1995). Pathological gambling among methadone patients. Drug and Alcohol Dependence, 39(2), 75-81. doi:10.1016/0376-8716(95)01141-K

Ferguson, C. J., \& Ceranoglu, T. A. (2014). Attention problems and pathological gaming: Resolving the "chicken and egg" in a prospective analysis. The Psychiatric Quarterly, 85(1), 103-110. doi:10.1007/s11126-013-9276-0

Fernández-Montalvo, J., \& Echeburúa, E. (2004). Pathological gambling and personality disorders: An exploratory study with the IPDE. Journal of Personality Disorders, 18(5), 500-505. doi:10.1521/pedi.18.5.500.51326

First, M. B., Gibbon, M., Spitzer, R. L., Williams, J. B. W., \& Benjamin, L. S. (1997). Structured Clinical Interview for DSM-IV Axis II Personality Disorders, (SCID-II). Washington, DC: American Psychiatric Press.

Gambling Commission. (2018). Statistics and research. Retrieved February 18, 2018, from http://www.gamblingcommission. gov.uk/news-action-and-statistics/Statistics-and-research/ Statistics-and-research.aspx

Grall-Bronnec, M., Wainstein, L., Augy, J., Bouju, G., Feuillet, F., Vénisse, J.-L., \& Sébille-Rivain, V. (2011). Attention deficit hyperactivity disorder among pathological and at-risk gamblers seeking treatment: A hidden disorder. European Addiction Research, 17(5), 231-240. doi:10.1159/000328628

Harpin, V. A. (2005). The effect of ADHD on the life of an individual, their family, and community from preschool to adult life. Archives of Disease in Childhood, 90(Suppl. 1), i2-i7. doi:10.1136/adc.2004.059006

Hesslinger, B., van Elst, L. T., Nyberg, E., Dykierek, P., Richter, H., Berner, M., \& Ebert, D. (2002). Psychotherapy of attention deficit hyperactivity disorder in adults. European Archives of
Psychiatry and Clinical Neuroscience, 252(4), 177-184. doi:10.1007/s00406-002-0379-0

Hodgins, D. C., \& Holub, A. (2015). Components of impulsivity in gambling disorder. International Journal of Mental Health and Addiction, 13(6), 699-711. doi:10.1007/s11469-015-9572-Z

Jacob, L., Haro, J. M., \& Koyanagi, A. (2018a). Post-traumatic stress symptoms are associated with physical multimorbidity: Findings from the Adult Psychiatric Morbidity Survey 2007. Journal of Affective Disorders, 232, 385-392. doi:10.1016/j. jad.2018.02.063

Jacob, L., Haro, J. M., \& Koyanagi, A. (2018b). The association between pain and suicidal behavior in an English national sample: The role of psychopathology. Journal of Psychiatric Research, 98, 39-46. doi:10.1016/j.jpsychires.2017.12.007

Jacob, L., Haro, J. M., \& Koyanagi, A. (2018c). The association between problem gambling and psychotic experiences: Findings from the Adult Psychiatric Morbidity Survey 2007. Schizophrenia Research. Advance online publication. doi:10. 1016/j.schres.2018.05.026

Jenkins, R., Meltzer, H., Bebbington, P., Brugha, T., Farrell, M., McManus, S., \& Singleton, N. (2009). The British Mental Health Survey Programme: Achievements and latest findings. Social Psychiatry and Psychiatric Epidemiology, 44(11), 899-904. doi:10.1007/s00127-009-0112-7

Kelleher, I., Ramsay, H., \& DeVylder, J. (2017). Psychotic experiences and suicide attempt risk in common mental disorders and borderline personality disorder. Acta Psychiatrica Scandinavica, 135(3), 212-218. doi:10.1111/acps.12693

Kessler, R. C., Adler, L., Ames, M., Demler, O., Faraone, S., Hiripi, E., Howes, M. J., Jin, R., Secnik, K., Spencer, T., Ustun, T. B., \& Walters, E. E. (2005). The World Health Organization Adult ADHD Self-Report Scale (ASRS): A short screening scale for use in the general population. Psychological Medicine, 35(2), 245-256. doi:10.1017/S0033291704002892

Kessler, R. C., Adler, L. A., Gruber, M. J., Sarawate, C. A., Spencer, T., \& Van Brunt, D. L. (2007). Validity of the World Health Organization Adult ADHD Self-Report Scale (ASRS) Screener in a representative sample of health plan members. International Journal of Methods in Psychiatric Research, 16(2), 52-65. doi:10.1002/mpr.208

Ledgerwood, D. M., Orr, E. S., Kaploun, K. A., Milosevic, A., Frisch, G. R., Rupcich, N., \& Lundahl, L. H. (2012). Executive function in pathological gamblers and healthy controls. Journal of Gambling Studies, 28(1), 89-103. doi:10.1007/ s10899-010-9237-6

Liu, W., Lee, G. P., Goldweber, A., Petras, H., Storr, C. L., Ialongo, N. S., \& Martins, S. S. (2013). Impulsivity trajectories and gambling in adolescence among urban male youth. Addiction (Abingdon, England), 108(4), 780-788. doi:10. 1111/add.12049

Ludolph, A. G., Kassubek, J., Schmeck, K., Glaser, C., Wunderlich, A., Buck, A. K., Reske, S. N., Fegert, J. M., \& Mottaghy, F. M. (2008). Dopaminergic dysfunction in attention deficit hyperactivity disorder (ADHD), differences between pharmacologically treated and never treated young adults: A 3, 4-dihdroxy-6-[18F] fluorophenyl-1-alanine PET study. Neuroimage, 41(3), 718-727. doi:10.1016/j.neuroimage.2008.02.025

Marazziti, D., Catena Dell'Osso, M., Conversano, C., Consoli, G., Vivarelli, L., Mungai, F., Di Nasso, E., \& Golia, F. (2008). Executive function abnormalities in pathological gamblers. 
Clinical Practice and Epidemiology in Mental Health : CP \& EMH, 4(1), 7. doi:10.1186/1745-0179-4-7

Matthies, S. D., \& Philipsen, A. (2014). Common ground in attention deficit hyperactivity disorder (ADHD) and borderline personality disorder (BPD) - Review of recent findings. Borderline Personality Disorder and Emotion Dysregulation, 1, 3. doi:10.1186/2051-6673-1-3

McClernon, F. J., \& Kollins, S. H. (2008). ADHD and smoking. Annals of the New York Academy of Sciences, 1141(1), 131-147. doi:10.1196/annals.1441.016

McManus, S., Meltzer, H., Brugha, T. S., Bebbington, P., \& Jenkins, R. (2009). Adult psychiatric morbidity in England, 2007: Results of a household survey. London, UK: National Centre for Social Research.

Miller, C. J., Flory, J. D., Miller, S. R., Harty, S. C., Newcorn, J. H., \& Halperin, J. M. (2008). Childhood ADHD and the emergence of personality disorders in adolescence: A prospective follow-up study. The Journal of Clinical Psychiatry, 69(9), 1477-1484. doi:10.4088/JCP.v69n0916

Miller, D. J., Derefinko, K. J., Lynam, D. R., Milich, R., \& Fillmore, M. T. (2010). Impulsivity and attention deficithyperactivity disorder: Subtype classification using the UPPS Impulsive Behavior Scale. Journal of Psychopathology and Behavioral Assessment, 32(3), 323-332. doi:10.1007/s10862009-9155-Z

Mowinckel, A. M., Pedersen, M. L., Eilertsen, E., \& Biele, G. (2015). A meta-analysis of decision-making and attention in adults with ADHD. Journal of Attention Disorders, 19(5), 355-367. doi:10.1177/1087054714558872

Oliva, F., Bramante, S., Portigliatti Pomeri, A., Carezana, C., Nibbio, G., Mangiapane, C., \& Maina, G. (2017). Personality traits and disorders among adult ADHD Patients: Is borderline personality disorder as common as we expect? European Psychiatry, 41, S258. doi:10.1016/j.eurpsy.2017.02.060

Ostojic, D., Charach, A., Henderson, J., McAuley, T., \& Crosbie, J. (2014). Childhood ADHD and addictive behaviours in adolescence: A Canadian sample. Journal of the Canadian Academy of Child and Adolescent Psychiatry, 23(2), 128-135.

Peters, E. M., Baetz, M., Marwaha, S., Balbuena, L., \& Bowen, R. (2016). Affective instability and impulsivity predict nonsuicidal self-injury in the general population: A longitudinal analysis. Borderline Personality Disorder and Emotion Dysregulation, 3, 17. doi:10.1186/s40479-016-0051-3

Peters, E. M., Balbuena, L., Baetz, M., Marwaha, S., \& Bowen, R. (2015). Mood instability underlies the relationship between impulsivity and internalizing psychopathology. Medical Hypotheses, 85(4), 447-451. doi:10.1016/j.mehy.2015.06.026

Peters, E. M., Balbuena, L., Marwaha, S., Baetz, M., \& Bowen, R. (2015). Mood instability and impulsivity as trait predictors of suicidal thoughts. Psychology and Psychotherapy: Theory, Research and Practice, 89(4), 435-444. doi:10.1111/papt.12088

Petry, N. M., \& Oncken, C. (2002). Cigarette smoking is associated with increased severity of gambling problems in treatmentseeking gamblers. Addiction (Abingdon, England), 97(6), 745-753. doi:10.1046/j.1360-0443.2002.00163.x

Philipsen, A., Graf, E., Tebartz van Elst, L., Jans, T., Warnke, A., Hesslinger, B., Ebert, D., Gerlach, M., Matthies, S., Colla, M., Jacob, C., Sobanski, E., Alm, B., Rösler, M., Ihorst, G., GrossLesch, S., Gentschow, L., Kis, B., Huss, M., Lieb, K., Schlander, M., \& Berger, M. (2010). Evaluation of the efficacy and effectiveness of a structured disorder tailored psychotherapy in ADHD in adults: Study protocol of a randomized controlled multicentre trial. Attention Deficit and Hyperactivity Disorders, 2(4), 203-212. doi:10.1007/s12402-010-0046-7

Rai, D., Hall, W., Bebbington, P., Skapinakis, P., Hassiotis, A., Weich, S., Meltzer, H., Moran, P., Brugha, T., Strydom, A., \& Farrell, M. (2014). Estimated verbal IQ and the odds of problem gambling: A population-based study. Psychological Medicine, 44(8), 1739-1749. doi:10.1017/S0033291713002195

Reid, R. C., McKittrick, H. L., Davtian, M., \& Fong, T. W. (2012). Self-reported differences on measures of executive function in a patient sample of pathological gamblers. The International Journal of Neuroscience, 122(9), 500-505. doi:10.3109/ 00207454.2012 .673516

Retz, W., Ringling, J., Retz-Junginger, P., Vogelgesang, M., \& Rösler, M. (2016). Association of attention-deficit/hyperactivity disorder with gambling disorder. Journal of Neural Transmission, 123(8), 1013-1019. doi:10.1007/s00702-016-1566-x

Rodriguez-Jimenez, R., Avila, C., Jimenez-Arriero, M. A., Ponce, G., Monasor, R., Jimenez, M., Aragües, M., Hoenicka, J., Rubio, G., \& Palomo, T. (2006). Impulsivity and sustained attention in pathological gamblers: Influence of childhood ADHD history. Journal of Gambling Studies, 22(4), 451-461. doi:10.1007/s10899-006-9028-2

Romo, L., Legauffre, C., Guilleux, A., Valleur, M., Magalon, D., Fatséas, M., Chéreau-Boudet, I., Luquiens, A., Vénisse, J. L., JEU Group, Grall-Bronnec, M., \& Challet-Bouju, G. (2016). Cognitive distortions and ADHD in pathological gambling: A national longitudinal case-control cohort study. Journal of Behavioral Addictions, 5(4), 649-657. doi:10.1556/2006.5. 2016.070

Romo, L., Rémond, J. J., Coeffec, A., Kotbagi, G., Plantey, S., Boz, F., \& Kern, L. (2015). Gambling and attention deficit hyperactivity disorders (ADHD) in a population of French students. Journal of Gambling Studies, 31(4), 1261-1272. doi:10.1007/s10899-014-9515-9

Sartorius, N. (2007). Stigma and mental health. Lancet (London, England), 370(9590), 810-811. doi:10.1016/S0140-6736(07) 61245-8

Saunders, J. B., Aasland, O. G., Babor, T. F., de la Fuente, J. R., \& Grant, M. (1993). Development of the Alcohol Use Disorders Identification Test (AUDIT): WHO collaborative project on early detection of persons with harmful alcohol consumptionII. Addiction (Abingdon, England), 88(6), 791-804. doi:10. 1111/j.1360-0443.1993.tb02093.x

Shek, D. T. L., Chan, E. M. L., \& Wong, R. H. Y. (2012) Associations between pathological gambling and psychiatric comorbidity among help-seeking populations in Hong Kong. The Scientific World Journal, 2012, 571434. doi:10.1100/ 2012/571434

Sobanski, E. (2006). Psychiatric comorbidity in adults with attention-deficit/hyperactivity disorder (ADHD). European Archives of Psychiatry and Clinical Neuroscience, 256(Suppl. 1), i26-i31. doi:10.1007/s00406-006-1004-4

Stickley, A., \& Koyanagi, A. (2016). Loneliness, common mental disorders and suicidal behavior: Findings from a general population survey. Journal of Affective Disorders, 197, 81-87. doi:10.1016/j.jad.2016.02.054

Stickley, A., Koyanagi, A., Takahashi, H., \& Kamio, Y. (2016). ADHD symptoms and pain among adults in England. Psychiatry Research, 246, 326-331. doi:10.1016/j.psychres. 2016.10.004 
Stockwell, T., Sitharthan, T., McGrath, D., \& Lang, E. (1994). The measurement of alcohol dependence and impaired control in community samples. Addiction (Abingdon, England), 89(2), 167-184. doi:10.1111/j.1360-0443.1994.tb00875.x

Theule, J., Hurl, K. E., Cheung, K., Ward, M., \& Henrikson, B. (2016). Exploring the relationships between problem gambling and ADHD: A meta-analysis. Journal of Attention Disorders. Advance online publication. doi:10.1177/1087054715626512

Vitaro, F., Arseneault, L., \& Tremblay, R. E. (1999). Impulsivity predicts problem gambling in low SES adolescent males. Addiction (Abingdon, England), 94(4), 565-575. doi:10. 1046/j.1360-0443.1999.94456511.x

Vrijsen, J. N., Tendolkar, I., Onnink, M., Hoogman, M., Schene, A. H., Fernández, G., van Oostrom, I., \& Franke, B. (2017). ADHD symptoms in healthy adults are associated with stressful life events and negative memory bias. Attention Deficit and Hyperactivity Disorders, 10(2), 151-160. doi:10.1007/s12402017-0241-x

Waluk, O. R., Youssef, G. J., \& Dowling, N. A. (2016). The relationship between problem gambling and attention deficit hyperactivity disorder. Journal of Gambling Studies, 32(2), 591-604. doi:10.1007/s10899-015-9564-8
Wardle, H., Griffiths, M. D., Orford, J., Moody, A., \& Volberg, R. (2012). Gambling in Britain: A time of change? Health implications from the British Gambling Prevalence Survey 2010. International Journal of Mental Health and Addiction, 10(2), 273-277. doi:10.1007/s11469-011-9319-4

Wareham, J. D., \& Potenza, M. N. (2010). Pathological gambling and substance use disorders. The American Journal of Drug and Alcohol Abuse, 36(5), 242-247. doi:10.3109/0095299 1003721118

Wickham, S., Taylor, P., Shevlin, M., \& Bentall, R. P. (2014). The impact of social deprivation on paranoia, hallucinations, mania and depression: The role of discrimination social support, stress and trust. PLoS One, 9(8), e105140. doi:10.1371/ journal.pone. 0105140

Wilens, T. E. (2004). Impact of ADHD and its treatment on substance abuse in adults. The Journal of Clinical Psychiatry, 65(Suppl. 3), 38-45.

Zulauf, C. A., Sprich, S. E., Safren, S. A., \& Wilens, T. E. (2014). The complicated relationship between attention deficit/ hyperactivity disorder and substance use disorders. Current Psychiatry Reports, 16(3), 436. doi:10.1007/s11920-0130436-6 